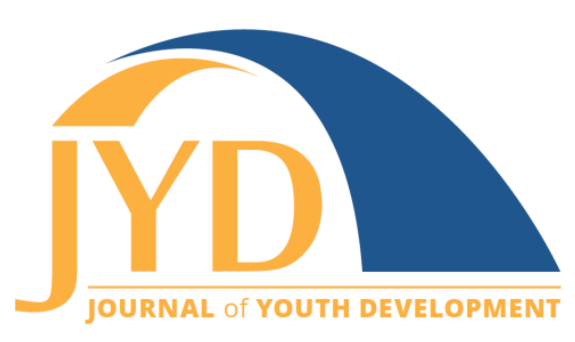

http://jyd.pitt.edu/ | Vol. 16 Issue 2-3 DOI 10.5195/jyd.2021.1030 | ISSN 2325-4017 (online)

\title{
Building Youth Infrastructure: Early Lessons From the Youth Systems Collaborative
}

\author{
Clare Ignatowski \\ University of Pennsy/vania and Creative Associates International \\ ignatows@sas.upenn.edu
}

Rachel Blum

Education Development Center

rblum@edc.org

Pia Saunders Campbell

International Youth Foundation

p.campbell@iyfnet.org

\section{Ricardo Perez-Pineda}

Education Development Center

rperez-pineda@edc.org

\begin{abstract}
In recent years the international youth development field has increasingly acknowledged that purposeful action at the systems level is critical for achieving positive outcomes for youth, sustainably, equitably, and at scale. In 2018 a group of international organizations formed the Youth Systems Collaborative, a community of practice whose aim is to promote international learning on youth systems change efforts. Building from the collective learning of this group, this paper offers a framework for understanding how widespread and sustained positive youth development outcomes can be achieved in low- and middleincome countries. Five enablers that advance systems change are presented: stakeholder collaboration; vision and goals; systems mapping; data, evaluation, and learning; and capacity development, as well as 4 domains within which system change occurs: policies, services and practices, norms and mindsets, and resource flows. Each of these 9 dimensions is illustrated with lessons learned from both U.S. and international youth systems change efforts. The paper concludes with a call to action for diverse system actors to apply these lessons as they support youth to reach their full potential.
\end{abstract}

Key words: international positive youth development, youth systems, systems change, sustainability

(cc) EY New articles in this journal are licensed under a Creative Commons Attribution 4.0 License. This journal is published by the University Library System, University of Pittsburgh and is cosponsored by the University of Pittsburgh Press. The Journal of Youth Development is the official peer-reviewed publication of the National Association of Extension 4-H Youth Development Professionals and the National AfterSchool Association. 


\section{Building Youth Infrastructure}

\section{Introduction}

Those in the youth development field often say: It is not youth who are disconnected; rather, it is our systems that are fragmented. Whether we look at Chicago or Mumbai, Charleston or Bamako, in most places a formal youth development system is unlikely to exist. Rather, there are multiple systems-education, health, justice, child protection, workforce development, social safety nets-that largely operate within silos, each claiming one "slice" of the young person's life. Each system has budgets, mandates, targets, and incentives to meet its own dimension of young people's needs. There is little coordination among these systems, and other key youth supports, such as peers and families, are often overlooked. This fragmentation leads to gaps in opportunity and services, redundancies, and inequities that are especially felt by marginalized youth: out-of-school youth, the rural poor, and girls and young women. Exogenous shocks, such as economic or political upheaval, violence, or a global pandemic, only underscore these inequities.

In recent years, the international youth development field has acknowledged that "thinking in systems" and purposeful action at the systems level is critical for achieving positive outcomes for youth-sustainably, equitably, and at scale. For instance, a literature review on international positive youth development ([PYD]; Alvarado et al., 2017) found that programs with positive evidence on sector-specific youth outcomes had engaged multiple stakeholders in multiple youth settings and that "the environment surrounding youth, including local community members and culture, plays a significant role in their ability to develop positively" (p. 42). According to two recent reviews of U.S. Agency for International Development (USAID) youth programming, international organizations expressed a high level of fatigue with narrowly scoped short-term activities and recommended that USAID adopt a systems lens when approaching youth development challenges (Blum et al., 2020; Ignatowski et al., 2020). USAID's Youth in Development Policy (USAID, 2012) and its PYD Framework (Hinson et al., 2017) call attention to cross-sectoral systems and an "enabling environment" that "encourages and recognizes youth, while promoting their social and emotional competence to thrive" (Hinson et al., 2017, p. 22). The question, therefore, should not be whether a systems approach is needed but rather how to best practice it. 


\section{Building Youth Infrastructure}

In 2017 a group of international organizations formed a community of practice called the Youth Systems Collaborative. ${ }^{1}$ This group's mission is to strengthen the global youth development field by promoting international learning on comprehensive systems change efforts that improve life outcomes for youth. Since systems change efforts often rely on case study methodology to generate knowledge, we developed case studies from our international experience, using a shared framework we call the Youth Systems Framework. In this paper, we present the framework, along with a range of domestic U.S. and international examples that illustrate lessons learned from each of the framework's nine domains. Case studies referred to in this paper include violence prevention in Guatemala, Honduras, and El Salvador; youth employment and skills development in Rwanda, Mozambique, and Tanzania; youth drop-out prevention in Philadelphia; and youth engagement in community health promotion in California. (See Table 1 for a summary of the case studies.) This discussion is followed by a summary "call to action" intended to contribute to the paradigmatic shift from a "project" to a "systems" approach in order to build more comprehensive, sustainable, and effective systems for youth.

\section{Table 1. Summary of Featured Youth Systems Case Studies by Location}

\section{Honduras and El Salvador}

Youth Outcome: Violence prevention through youth, community, private sector, \& government engagement Initiatives / Funding: Alianza Joven/Youth Alliance (2004-08), Regional Youth Alliance (2008-13), Outreach Center Global Development Alliance/Honduras (2012-15), Crime and Violence Prevention Project (2013-20), Proponte Más/Secondary Violence Prevention (2016-20) / USD 78.5 million

Select Local Stakeholders: Central American Integration System; municipal governments; Salvadoran Institute for the Comprehensive Development of Children and Youth; Salvadoran Ministry of Justice and Public Security; Honduran Children, Adolescent, and Family Directorate; Institute for the Care of Child Offenders

Lead Implementing Partner / Funder: Creative Associates International / USAID

\section{Guatemala}

Youth Outcome: Youth violence prevention and re-integration of former gang members

Initiative / Funding: Desafío Joven/Youth Challenge (2008-09), Youth Alliance (2004-08) / USD 2.1 million Select Local Stakeholders: Jóvenes Contra la Violencia/Youth Against Violence; Coordinating Committee of Agricultural, Commercial, Industrial and Financial Associations; Rotary Club; churches; local NGOs Lead Implementing Partner / Funder: Creative Associates International / USAID

\footnotetext{
${ }^{1}$ The Youth Systems Collaborative was founded by Bonnie Politz and Clare Ignatowski in 2017 and formally launched in 2018. Today this group involves nine international organizations: Creative Associates International; Education Development Center, Inc. (EDC); International Youth Foundation; RTI International; FHI 360; Save the Children USA; Catholic Relief Services; the Aspen Institute; and Making Cents International.
} 


\section{Building Youth Infrastructure}

Table 1. (continued)

\section{Mozambique and Tanzania}

Youth Outcome: Work readiness and employment for vulnerable urban and peri-urban youth

Initiative / Funding: Via: Pathways to Work (2015-21)/ USD 19.7 million

Local Stakeholders: Network of 35+ youth-serving organizations. In Tanzania: Technical Vocational Education \& Training Authority (Tanzania TVET); Ministry of Education, Science and Technology; Tanzanian Entrepreneurship and Competitiveness Centre. In Mozambique: Instituto de Formação Profissional e Estudos Laborais Alberto Cassimo; Instituto Nacional de Emprego (Mozambique TVET); State Secretariat for Youth and Employment; Autoridade Nacional de Educação Profissional

Lead Implementing Partner / Supporting Partner: International Youth Foundation / The Mastercard Foundation

\section{Rwanda}

Youth Outcome: Work readiness and employment for vulnerable, out-of-school, and rural youth Initiatives / Funding: Akazi Kanoze (2009-16), Akazi Kanoze II (2014-17), Huguka Dukore Akazi Kanoze (2017-21) / USD 40 million

Select Local Stakeholders: Network of 65+ youth-serving organizations; Ministry of Education; Ministry of Youth, Workforce Development Authority; Rwanda Polytechnic; National Employment Program; Private Sector Federation; 2,500 businesses; Goshen Finance, RIM Ltd., Umutanguha Finance; district mayors' offices; youth savings groups; youth leaders

Lead Implementing Partner / Funding and Supporting Partners: EDC / USAID; The Mastercard Foundation

\section{State of California, USA}

Youth Outcome: Engagement of youth and their communities in strategic advocacy and policy innovation for healthier, more resilient communities

Initiative / Funding: Building Healthy Communities (BHC) (2010-20), USD 1 billion

Lead Implementing Partners and Funders: Diverse across 14 sites, including for example, the Orange County Human Relations Commission for the Santa Ana BHC/ The California Endowment

\section{City of Philadelphia, USA}

Youth Outcome: Increase high school graduation rates and re-engage youth who have dropped out Initiative / Funding: Project U-Turn / leveraged funds of USD 272 million

Select Local Stakeholders: School District of Philadelphia; Mayor's Office of Education and Department of Human Services; United Way; JEVS Human Services; Public Citizens for Children and Youth; Philadelphia District Attorney's Office; youth representatives Managing Partner / Funder: Philadelphia Youth Network / William Penn Foundation 


\section{Building Youth Infrastructure}

\section{Definitions and Influences}

This increased attention to systems thinking in international youth development compels us to clarify three terms: systems, sustainability, and scale. USAID (2014) defines systems as "interconnected sets of actors - governments, civil society, the private sector, universities, individual citizens and others-that jointly produce a particular development outcome" (p. 4). Although system dynamics are universal, we distinguish between "system strengthening" within a single sector (such as reform of a public education or health system) and multi-system collaboration, which involves crossing the boundaries of traditionally defined systems to reframe how they interact on behalf of young people, their families, and their communities. Moreover, to achieve positive change, a range of stakeholders must acknowledge the system dynamics that shape or impede their desired outcomes and make course corrections when those outcomes are not being achieved (Kania et al., 2018; Meadows, 2015; Stroh, 2015). For instance, the field of market systems development aims to facilitate shifts in those systems so that the incentives and behaviors of market actors are more inclusive of and beneficial to the poor (Conroy \& Kessler, 2019; Nippard et al., 2014).

Our understanding of systems thinking contains the expectation of both sustainability and scale. USAID (2014) defines sustainability as "the ability of a local system to produce desired outcomes over time" (p. 5). Sustainable systems have "built-in durability and adaptability that allows actors and their interrelationships to accommodate shocks and respond to changing circumstances" (p. v). Working through existing systems also implies scaling youth outcomes. For instance, the international education sector views a systems approach as a means by which education outcomes are scaled (Gibbs et al., 2020). Perlman Robinson et al. (2020) note that scaling "represents a range of approaches-from deliberate replication to organic diffusion to integration into national systems - that expand and deepen impact leading to lasting improvements in people's lives" (p. 2).

Collectively, the body of work on systems thinking only partially paints the picture of youth systems because of the cross-sectoral nature of youth development. We define a youth system as a group of diverse actors that co-create, positively or negatively, a youth development outcome or set of outcomes. Supportive youth systems are those in which multiple stakeholders deliver critical supports and opportunities that enable all (or large numbers of) youth to progress through adolescence and young adulthood to become healthy, engaged, and successful adults. These partnerships engage diverse stakeholders, including various levels of government, non-governmental organizations (NGOs), private sector businesses, community 


\section{Building Youth Infrastructure}

associations, families, and young people themselves, and they are usually cross-sectoral. In this paper, we present and apply a youth systems lens that accounts for these multiple sub-systems and institutions that young people interact with and that influence their life transitions.

Youth systems change efforts cannot be reduced to projects that seek to deliver a particular service to youth, nor to discrete efforts at institutional capacity building. They are also not replication efforts that aim to scale particular interventions across places or populations. In short, while youth systems change efforts can and do benefit from donor funding and initiatives and can contain projects and capacity-building efforts within them, they are fundamentally different from short-term projects. They are locally owned and managed initiatives that bring together diverse stakeholders to solve systems-level problems preventing the flow of resources to youth and to develop local solutions. International development organizations do have a facilitative role in these systems change efforts, rather than direct service delivery or policymaking roles.

\section{Introduction to the Youth Systems Framework by the Youth Systems Collaborative}

The Youth Systems Framework was developed to help international youth development partners learn from their own systems-oriented work in low- and middle-income countries (LMICs). The framework comprises nine domains and enablers for investigating youth systems change efforts, as illustrated in Figure 1.

While the Youth Systems Framework was informed by the collective experience of several organizations, it was initially derived from a literature review of the domestic U.S. youth systems field, spanning 40 years of experience (Academy for Educational Development, 2003; Cytron, 2010; Equal Measure, 2019; Walsh, 1999), which revealed the factors most critical to successful youth systems efforts and what could be expected from these efforts over time (Ignatowski, 2018). Three notable, current initiatives are Harlem Children's Zone, StriveTogether, and Collective Impact, which build on earlier pioneering work such as New Futures (1987-93). International systems frameworks beyond the youth sector were also reviewed (Academy for Educational Development, 2004; Conroy and Kessler, 2019; Management Systems International, 2016; Nippard et al., 2014; USAID 2014). Overall, the review included 45 documents: implementation frameworks, case studies, and rigorous external 
evaluations. ${ }^{2}$ Of course, conditions in domestic U.S. cities and counties differ radically from those in LMICs, but the Youth Systems Collaborative seeks to determine how system factors differ or manifest themselves specifically in LMICs, and how we might promote dialogue and learning across high-income and LMIC change makers.

Figure 1. Youth Systems Framework by the Youth Systems Collaborative

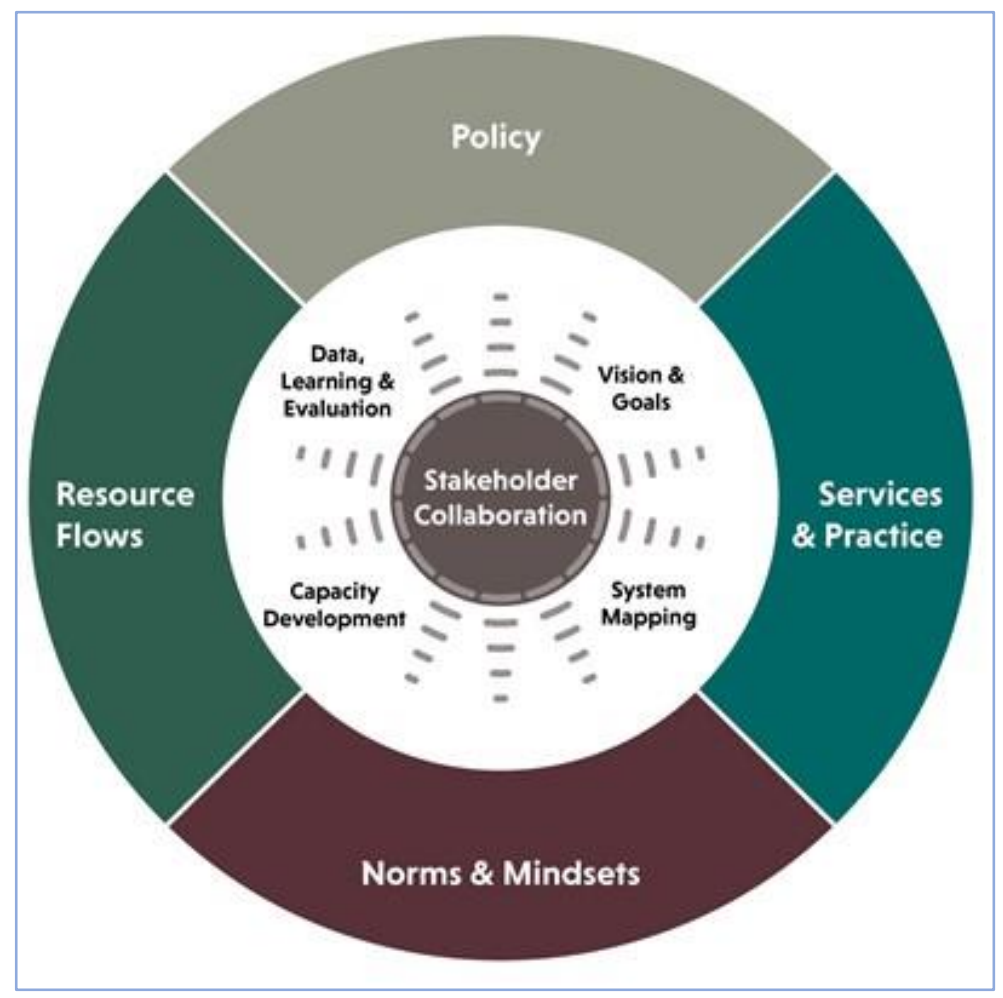

The Youth Systems Framework is comprised of four domains: policy, services and practices, norms and mindsets, and resource flows. System change takes place within these major fields. Although they are depicted as separate, they are in fact deeply imbricated with one another, e.g., policy shapes how services are delivered, and norms and mindsets inform policy. Their arrangement reflects two well-known frameworks: the "systems iceberg" and the Six Conditions of Systems Change (Kania et al., 2018). In the circle's center is stakeholder collaboration which is at the heart of systems change: the relationships among core stakeholders responsible for youth infrastructure, as well as the collective commitments they make both as individuals and

\footnotetext{
${ }^{2}$ Systems frameworks were reviewed for the degree to which they were relevant to youth development inclusive of both public and private sector factors; and the degree to which they integrated both descriptive and prescriptive dimensions. ("Descriptive" denotes domains or fields of a system; "prescriptive" denotes actions to facilitate systems change.) The lack of a single framework that integrated all of these dimensions motivated the creation of the Youth Systems Framework.
} 


\section{Building Youth Infrastructure}

institutions. Stakeholder collaboration along with the four other enablers-vision and goals; systems mapping; data, monitoring and evaluation; and capacity building-are key activities that propel change processes.

The Youth Systems Collaborative uses a series of questions that accompany the framework to reflect on the dynamics of youth systems practice. To date, we have found value in using a common framework, applying these questions retrospectively through case study methodology to deepen our understanding of how youth systems change has occurred in LMICs. We have begun to explore applications of the framework across all phases of systems work. For example, the framework can serve as a tool for diverse stakeholders to understand a system's dynamics and develop collaborative strategies to improve youth outcomes. It can stimulate shared learning agendas among local service providers to reflect on the factors that are impacting youth outcomes (positively or negatively). It can also be used to facilitate the co-design of donor-funded projects to ensure they consider all aspects of the youth system from the outset.

The framework's domains and enablers are described below and supported by examples from practice.

\section{Enabler 1: Stakeholder Collaboration}

Equitably addressing youth needs at scale requires many local actors coming together and taking responsibility for creating a sustainable infrastructure for youth. ${ }^{3}$ There is strength and resilience in the collaboration of diverse actors-civil society, including young people themselves; government; and the private sector-working together, usually across multiple sectors (e.g., education, employment, justice and security, health), each with distinct roles. Funding partners are an integral part of this ecosystem, not separate from it. Stakeholder collaboration entails creating space for everyone, especially those not already at the table; managing power imbalances and conflict; aligning motivations, value propositions, and roles; and addressing competing behaviors and duplication-all toward a "win-win" situation.

For positive systems change to occur, often it is necessary to identify and resource an intermediary or backbone organization that plays a facilitative role, holding space for all

\footnotetext{
${ }^{3}$ The term infrastructure for youth builds from the metaphor of a physical infrastructure; it refers to the supportive set of services, opportunities, and relationships that enable youth to thrive in much the way that water, electricity, roads, Internet, etc. enable communities to survive. This metaphor forces us to acknowledge that youth infrastructures require financial investment and careful planning and coordination exactly as physical infrastructures do. (See Academy for Educational Development, 2003.)
} 


\section{Building Youth Infrastructure}

stakeholders and helping drive momentum (Kania \& Kramer, 2011; Turner et al., 2012). Relationship building, trust, and clear ongoing communication enable the alignment of stakeholder interests. Because real change cannot occur without some conflict, successful systems efforts allow both nurturing relationships and confrontation of the status quo. A culture of trust and accountability arises when system actors establish binding commitments, collaboration instruments, and accountability systems, and when they strive to increase and improve communication among one another and with the public.

There is no single pathway to building stakeholder collaboration, but when efforts feed the incentives of each stakeholder, they become more willing to expand or adjust their respective roles and to be accountable to the collective effort.

- Local alliance models have been successful in Rwanda, Kenya, and the Philippines (EDC, 2016), bringing together line ministries, the private sector, youth leaders, service providers, and community organizations to coordinate and improve youth program service delivery. In Rwanda, district mayors' offices were incentivized by a national decentralization effort to create multi-stakeholder Youth Development Alliances that included youth as decision makers. In Kenya, nine counties established County Youth Employment Compacts that mobilized $\$ 5.6$ million in county government funds toward youth employment goals.

- Building Healthy Communities, funded by The California Endowment initiative in 14 lowincome communities across California, meaningfully engages young people in policymaking and organizing to promote health concerns they have identified, such as toxic stress related to school discipline.

Case study: A low-cost, adaptable model that meets a felt need can be sustained at the local level by the key stakeholders affected by the problem.

In the mid-2000s in Guatemala, Honduras, and El Salvador, gang-related violence had reached epidemic proportions. Many economically distressed communities recognized that young people needed safe places to spend time after school, but the first recreation centers failed, as youth could not safely cross gang territories. Families would not let their children leave the house for fear that they would be lured into gangs or caught in crossfire.

In Guatemala, after seeing a model in Jamaica of a "youth house" in a community setting, a set of partners representing faith-based groups, municipal governments, and community development associations (Asociaciones de Desarrollo Comunal, or ADESCOs) worked with 


\section{Building Youth Infrastructure}

Creative Associates International to form the first three Outreach Centers. With very modest funds from USAID, the centers had only one paid staff member, so they reached out to volunteers from the community who were willing to share their time with and mentor young people (ages 10 to 15), using musical instruments, sports, games, and access to computers. A memorandum of understanding was signed between the mayor's office (which provided the staff funding), the faith-based groups, and the ADESCOs to establish the centers.

The model was then replicated in Honduras and El Salvador. In Honduras, 62 self-sustaining centers in six municipalities now serve more than 38,000 youth, with contributions of nearly $\$ 10$ million from the public and private sectors. In El Salvador, as of 2019, approximately 160 centers serve 40,000 community members, many of which are now funded by the municipal governments.

Nearby residents have said that after an outreach center was created, they felt safe moving about the streets again. As a 2016 evaluation noted, while centers are not a solution in and of themselves to the complex problem of rule of law and violence, they are a key component of a primary violence prevention strategy that is part of a larger ecosystem of efforts (Roth \& Walsh, 2016). The community and youth engagement fostered through the centers is complemented by the engagement of municipal leaders in other violence prevention approaches, such as crime and violence prevention committees and crime observatories that track incidents of crime in the community.

\section{Enabler 2: Vision and Goals}

A vision for PYD is a shared image of what we would like to see created with and for young people that allows them to be healthy, productive, and happy. It is backed up by "North Star" goals and high-level goals that concretize what success looks like, expressed in targets. Visions and goals are jointly held across the entire network of partners, from top-level policy decision makers to those implementing policies and practices to the intended beneficiaries. Without a vision, there can be no improvement, and without high-level goals, there is no way to ensure accountability for the change process. They are the "glue" that holds disparate partners together, working in diverse ways toward a common objective.

- In Rwanda, the government articulated a clear national vision for workforce development and a tangible goal of creating 200,000 off-farm jobs per year, solidifying a 


\section{Building Youth Infrastructure}

massive reform process that mobilized four ministries, local government, the private sector, and seven international donors.

Case study: Diverse stakeholders are motivated to come together when they can share a broad vision buttressed by clear, measurable targets for success.

Since 2006, when Philadelphia's Project U-Turn was launched, the city has been guided by its collective vision: to unify partners to increase graduation rates and to prepare young people for future opportunities. The launch of Project U-Turn coincided with a groundbreaking study by the Philadelphia Youth Network, the Johns Hopkins University, and the University of Pennsylvania. The study, Unfulfilled Promise (Neild \& Balfanz, 2006), documented for the first time the multi-dimensional problem of Philadelphia's drop-out crisis (an on-time graduate rate hovering at about 50\%) and called for action on multiple fronts. As a result, a multi-sectoral collaborative was formed, comprising the School District of Philadelphia, the Mayor's Office of Education, the city's Department of Human Services, family court, local foundations, youth service providers, charter schools, youth advocacy groups, families, and young people.

The Philadelphia Youth Network serves as the backbone organization for Project U-Turn, a multi-system, multi-stakeholder campaign organized around two specific goals:

- Re-engagement of youth who have dropped out of school: Increase the percentage of those who re-engage to $70 \%$ and ensure that $50 \%$ of them earn their high school diploma or equivalency through high-quality programs.

- Drop-out prevention: Reduce the drop-out rate from $50 \%$ to $20 \%$.

A hallmark of the initiative is its work on both sides of the "school divide": drop-out prevention for youth currently in school and re-engagement of youth who have recently dropped out. Since its inception, Project U-Turn has provided more than 28,000 re-engagement opportunities, leveraged and/or realigned $\$ 272$ million from public and private sectors, and continued to commission studies to assess the needs and realities of Philadelphia's young people and to inform program-based interventions and education policy decisions. 


\section{Building Youth Infrastructure}

\section{Enabler 3: Systems Mapping}

Improving youth outcomes requires an understanding of the parameters and dynamics of the system that produces those outcomes. It involves developing a collective understanding of who is (or should be) part of the system, who has power and who does not, and who has formal roles and responsibilities and who is operating informally. Identifying the institutional and individual actors in a system means also understanding their capacities, the rules that govern them, the patterns of behavior among them, and existing incentive (or disincentive) structures. Much of systems work is place-based, which involves understanding the unique assets and challenges facing a community, city, county, or other geographic unit, and how power and status play out through geography. Even when systems change efforts span a wide geographic area, e.g., with national policy reform, those efforts are felt in specific locations with specific populations.

Systems mapping can be a more or less formal learning process, depending on the effort, but it must be participatory. Through a shared process of learning about the system, stakeholders get to know one another, often in new ways. They may be surprised by blind spots-e.g., discovering that they have not been hearing excluded groups, or that routine procedures no longer work, or that the existing digital divide has become even more pronounced during the COVID-19 pandemic. An acute crisis can highlight these blind spots and bring energy to stakeholders seeking a solution.

- In Tunisia, local NGOs were supported by FHI 360 to lead a participatory process, called Whole System in a Room, to map and then engage a broad range of multi-sectoral stakeholders, including parents and members of security services, to respond to youth's participation in violent extremist groups. Involving youth in the community mapping exposed gaps in services, such as a lack of safe spaces for young people, that the adult decision makers had not known about.

- Informal mapping in Tanzania revealed a new key stakeholder in the youth employment system: the TVET zonal offices. These offices serve as gatekeepers for curriculum approval and had to be actively engaged in order for TVET reform to succeed.

- In Rwanda, youth training providers, networked through the Huguka Dukore Akazi Kanoze initiative, created "One Voice," a joint labor market mapping process. This collaboration reduced fatigue within the private sector associated with data collection, encouraged local government support, prevented a flooding of the market in limited job categories, and built new operational relationships based on trust. 


\section{Building Youth Infrastructure}

\section{Enabler 4: Data, Evaluation, and Learning}

A resilient youth system is one in which actors value knowledge, data, and evidence and apply them to the process of stimulating change in the system. Data tell policymakers and practitioners whether, and how, a particular intervention is working and whether investments are well-spent. System actors use data as timely feedback to determine whether they are working together effectively to improve youth outcomes, if the identified pathways for change are producing results, and if course corrections are needed. Data are also used to assess the systemic change process, including the quality and strength of relationships. Information may come from formal data collection, such as regular performance monitoring and rigorous evaluation, and from informal, tacit observational learning between partners. At a wider scope, when used as an advocacy tool, data can influence others in the mindsets, policies, and practices that influence youth outcomes.

Case study: When stakeholders embed rigorous data, evaluation, and learning into their business processes, the evidence often motivates other system actors to embrace a shared vision for change and ultimately improve youth outcomes.

In Tanzania, traditionally the performance of TVET Centers had been measured solely by enrollment, and this approach failed to demonstrate a need for systems change. The Via Initiative introduced to the centers a new way to regularly review intake and performance data, including student learning and employment outcomes. Having an ongoing common performance measurement system motivated the centers to invest in improvements to their services, and they began to strive for improved youth outcomes in learning and employment.

To complement the internal data tracking systems, an external evaluation firm conducted a rigorous evaluation-a tracer study with a comparison group-to confirm the outcomes the centers had observed and provide evidence that the investments made across the TVET system were paying off at the institutional level. A participatory outcome-harvesting ${ }^{4}$ exerciseinvolving TVET administrators, managers, and educators; national curriculum development authorities; the private sector; and young people-was introduced to identify changes, both expected and unexpected, in practices and policies at the systems level. "Stories of change" produced by students, trainers, and employers effectively influenced government policy makers

\footnotetext{
${ }^{4}$ Outcome harvesting is an evaluation approach that helps identify observable and significant changes in complex environments. It measures outcomes (changes in individuals, organizations, and systems) that can be attributed to an intervention or initiative. These outcomes must meet certain criteria, such as being sustainable, observable, and backed by evidence.
} 


\section{Building Youth Infrastructure}

to advocate for the integration of enhanced life skills content and new pedagogy across the system. (DevLearn, 2019)

\section{Enabler 5: Capacity Development}

Individuals, organizations, and youth systems must have the capacity to deliver the support that youth need, and they must be able to learn from experience and craft changes to the system as new information emerges or as conditions change. Technical knowledge is not the only capacity needed, but also a range of leadership and people skills, including especially facilitation skills. Capacity emerges from individuals who know a community or system "from the bottom up" and whose longevity and reputations confer legitimacy to a group or institution.

One of the most powerful forms of capacity building in youth systems is experiential learning, which goes beyond classes, training, and conferences; it involves a range of formal and informal hands-on experiences, such as mentoring, coaching, peer exchange and feedback, observation, and implementation research. Learning through these modes requires a safe space for system actors to engage in inquiry and idea generation. This is especially true for organizations led by youth who, new to navigating the system, often need space to learn from adults and from one another.

- Legacy organizations from international development projects can remain systems actors and have influence long after projects end. In Rwanda, Akazi Kanoze Access took on the role of a local resource for technical assistance and capacity development in workforce development, and they now provide teacher training and quality assurance services to the Rwandan government.

- Building capacity and demand for data and youth voices can lead to more relevant supports and services for young people and facilitate collaboration for change. In Mozambique and Tanzania, a shared approach to tracking data and measuring results was reinforced through quarterly workshops and partner meetings, which both provided an opportunity to practice using the data together and created more demand for this information across the system. TVET Centers now use genderdisaggregated enrollment data to identify training courses that need greater gender parity, and the centers hold youth feedback sessions to inform and adjust their efforts.

- Capacity building in Honduras involved mentorship, systematized methodologies, and a structured "learning by doing" experience to establish new outreach centers in high-crime neighborhoods. Overseen by the well-established 


\section{Building Youth Infrastructure}

FUNADEH and part of Creative's USAID-funded Alianza Joven project, it was part of an effort to build local capacity for sustainability. Today, FUNADEH has leveraged over $\$ 2.7$ million in investments from 50 businesses and almost 3 times as much from local and government agencies, universities, and NGOs.

\section{Domain 1: Policies}

Policies, laws, standards, rules, and regulations offer the formal framework within which a youth system operates. For youth, influential policies may reside at the level of a public national or subnational entity within an individual public or private organization (such as an employer, training provider, industry standards body, or financial regulatory agency), or the policies may reside within a network, such as a school district or teachers union. In some contexts, formal policies are an important prerequisite for system change to occur; in other contexts, formal policies may be in place but lack a feasible implementation strategy. System change may involve advocacy for and formation of a new policy, enforcement of existing rules, or the removal of laws and policies that act as barriers to youth.

- Youth are critical actors for policy change. With the engagement of the multilateral organization, the Caribbean Community (CARICOM), a diverse set of stakeholders, including 267 youth from 13 nations, jointly developed the Caribbean Youth Advocacy and Action Agenda on Violence Prevention (AAA) in 2019. The AAA called for juvenile justice reform and engagement of families, communities, and schools in addressing such controversial issues as toxic masculinity, bullying, corporal punishment, and genderbased violence. Presented at the 2019 Caribbean Summit on Youth Violence Prevention, organized by USAID's Community, Family, and Youth Resilience Project, the youth-led policy and practice recommendations were adopted by CARICOM. To date, 70 youth and community-based leaders are using the online AAA Toolkit and advocacy course to create cultures of peace in their communities.

Case study: Systems change involves equity: empowering underserved communities to flex their civic and political power and to include the perspectives of youth in that process.

Funded by The California Endowment, the Building Healthy Communities Initiative (2010-20) works with 14 low-income communities across the state as "proving grounds for communitydriven policy and practice innovations that . . . serve to inform and advance statewide health policy and systems change" (The California Endowment [TCE], 2016, p. 18). At the 5-year mark, the Initiative observed: 


\section{Building Youth Infrastructure}

For all of the attention heaped upon the roles that "good data," "research effectiveness, " and "innovative approaches" have in driving public policy, the building of healthier communities is fundamentally a game of power, voice and advocacy. Plugging the voice of community into the right kind of political power grid will do more to create health and wellness than any other single intervention. (TCE, 2016, p. 4)

The active engagement of youth of color and youth from poor, white, rural communities in all 14 sites significantly shaped the creation of one of four Transformative Policy Domains: "Health Happens in Schools." Hundreds of youth advocates brought their lived experience of trauma and stress to the public health dialogue, arguing assertively that harsh school discipline and suspension practices - the front end of the school-to-prison pipeline-should be understood as a critical community wellness issue. Unhealthy, disengaged, or defiant behavior in the immediate term leads to increased incarceration in the intermediate term and to significantly increased rates of chronic health issues and depression in the long term. As a result, the California State Board of Education piloted a landmark accounting system that included suspension/expulsion and chronic absenteeism as key indicators (THP Capacity Advisors, 2017). In 5 years, statewide school suspension rates had dropped by $63 \%$.

\section{Domain 2: Services and practices}

Services include the opportunities, supports, networks, and information that youth need to be successful. Education and health care are the most common services, but financial services, civic engagement, advocacy, juvenile justice, and violence prevention are also important. Services can be private, public, or a hybrid. A strong and sustainable youth infrastructure means that a community (and ultimately a nation) offers the services needed by its young people; that the services are accessible to all youth, especially to the marginalized; and that the services form a continuum that meets youth's developmental needs-physical, cognitive, social, and emotional-as they transition to adulthood. Practices refers to the behaviors of those who either are directly in contact with youth (e.g., teachers, mentors, employers, family members) or indirectly affect them through institutional or policy decision making (e.g., NGO and political leaders, school administrators).

Ensuring that all youth can access the right support at the right time is an ongoing challenge. Particularly in LMICs, youth programs often overlook the needs of out-of-school youth and other 


\section{Building Youth Infrastructure}

marginalized groups. While services are the visible and tangible part of a youth infrastructure, they are also shaped by the mindsets and relationships-between youth and adults and across system partners-that undergird them.

Service delivery reform should result in measurable improvements to youth outcomes. Youth systems work thrives within a dynamic network of providers who are continuously iterating improvements backed by data and evaluation and are communicating this learning to peer organizations. This flexible, modular approach allows for adaptation of services that are costeffective and "good enough" to meet the changing needs of youth within available resources.

- In high-crime communities, traditional education and training services often do not address youth's foundational needs for support and structure from those closest to them-their families. In Honduras, through USAID's Proponte Màs project, communitybased organizations (CBOs) adopted a family counseling model in which trained counselors, parents, youth, and community service providers used a practical problemsolving methodology with youth at high risk of joining gangs. An assessment conducted after 6 months of counseling found a 74\% reduction of risk for youth joining a gang and a $47 \%$ increase in family coherence, a protective factor.

Case study: High-quality services that are flexible and affordable, offered by multiple delivery channels, and backed by tangible evidence can be a powerful attractor for other stakeholders to contribute to youth outcomes at scale.

In 2008, Rwanda had ambitions of attaining middle-income country status; however, the quality of education was poor and disconnected from the demands of the private sector. Employers preferred to recruit university graduates, usually by word of mouth, rather than from the TVET system.

A decade later, service providers on the ground have made a key difference in aligning themselves with the interests and resources of youth and the private sector. For instance, under a USAID- and Mastercard-supported series of projects implemented by EDC, a network of 65+ private service providers introduced a number of innovations in service delivery, including curriculum informed by private sector demand, learner-centered pedagogy, soft skills development, work-based learning, and entrepreneurship coaching. Partners now have the space to continually iterate with and learn from one another. Common monitoring and evaluation protocols-including listening to youth and to employers-are instrumental to the learning process. 


\section{Building Youth Infrastructure}

By improving the quality of services, the provider network was able to demonstrate tangible gains in skills among 82,000 youth in 25 of the 30 districts, with a $65 \%$ employment rate among workforce graduates. This success prompted the government to integrate a soft skills curriculum into 450 secondary schools, and then into the entire national secondary education and TVET systems, reaching an average of 258,000 young people per year.

Less likely to be passive recipients now, youth participants are actively organizing countless savings and lending groups across the country, and young leaders provide peer mentoring with support from their teachers. The private sector has also been drawn to the high-quality services: at least 2,500 businesses have delivered services such as work-based learning and internships, and many are subsidizing these services. Financial service providers are also adapting and expanding their products to meet youths' drive to establish their own businesses.

\section{Domain 3: Norms and Mindsets}

Norms and mindsets are invisible, but they have an outsized influence on a society's policies and practices. Those related to youth are deeply connected to more general societal attitudes and culture, such as what kind of work is valued and how gender is understood. While it is not an easy or simple process, shifts in norms and mindsets can occur-sometimes through a combination of community action, advocacy and policy reform, and sometimes through incremental improvements in practice.

- In Mozambique, Rwanda, and Tanzania, mindsets among employers markedly shifted regarding the value of hiring once stigmatized "out of school youth" or "TVET-educated youth" when they saw how well these youth performed on the job after attaining important soft skills through high-quality training programs.

Case study: Mindset shift requires listening to those who have been pushed to the margins, interrupting our routine ways of thinking, and responding in new ways.

In 2006, a neighborhood in Guatemala was shocked when 30 local young people were murdered in a period of only 6 months. Rumors circulated that some of the killings were by police, which would not be surprising because, at the time, heavy-handed anti-gang tactics (mano dura) were employed by law enforcement, and there was little awareness of the notion of crime prevention, as opposed to crime fighting. Furthermore, there was a widely held belief 


\section{Building Youth Infrastructure}

of "once a gang member, always a gang member," and all low-income youth were stigmatized as potential gang members.

On the other hand, both the Catholic and the evangelical churches were working to actively protect young people from violence. At one critical meeting hosted by a church, former gang members were asked to talk about their difficult experience of leaving a gang and what led them to join in the first place. Participants could hardly believe that these gang members were real, so rare was this kind of discussion in Guatemalan society. From there was born the idea of creating a reality TV show based on ex-gang members' experiences and their efforts to reintegrate into the community. With USAID support, the show Challenge 10 centered on 10 former gang members working to start their own businesses. The show received national and international attention, and Challenge 100 was then created to integrate 100 former gang members into the labor force. Both shows succeeded in raising awareness about the private sector's role in supporting youth who had left gangs.

Once their mindset had successfully shifted-gang activity was not in fact inevitable and irremediable-the community realized the need to create pathways out of gangs and to help their young people avoid joining gangs by offering safe spaces for them to gather. This collective effort resulted in the identification of 13 risk factors prevalent in the former gang members' lived experience; from this, some 40 tools and approaches were developed for communities to mitigate these risks for youth. Most importantly, the mindset has shifted from a crime-fighting paradigm, in which policing is imposed on the community, to a public health and empowerment model of violence prevention, in which community members-including youthcan and do act to change the conditions that lead to violence.

\section{Domain 4: Resource Flows}

Resources refers to the strategic financial and in-kind investments that system actors contribute to PYD—both tangible and intangible. No single actor is responsible for all the investments necessary for true youth development; it is a shared responsibility. While sometimes more resources are needed to achieve a youth development goal, often there are sufficient, but misaligned, resources.

Sometimes services must be modified, streamlined, and prioritized to make them more affordable. This often requires reforming the role of entities with resources-e.g., shifting the 


\section{Building Youth Infrastructure}

role of government or donors from providing direct service delivery to assuming a policy, accountability, and quality control function. Sometimes it matters who is investing resources, e.g., technical input from the private sector is a critical element of a well-functioning workforce development system, even when there are sufficient financial or physical resources from the public sector.

- In Rwanda and Senegal, the Ministries of Education participated with EDC in costanalysis exercises to determine the additional incremental costs associated with offering life skills and work readiness education to secondary school students. In both cases, Ministry officials welcomed this new exercise. Rwandan partners then adopted the new curriculum for as little as USD 5 per student over three years (Cyr, 2017).

- In Mozambique and Tanzania, innovations in service delivery were widely and sustainably adopted by the system when the resource burden was reallocated across multiple stakeholders. More resources were required for enhanced course content and wrap-around services for TVET students. After validating the feasibility of the innovations, the Tanzanian government managed this resource gap by increasing student fees and expanding the role of the national TVET teachers training college as a center of excellence for the innovations.

\section{Call to Action}

Our application of the Framework has revealed insights about youth systems change in LMICs that are likely to exist more widely. Going forward, we suggest that the Framework be used to guide the development of new systems change initiatives and to monitor and evaluate progress. (Having multiple stakeholders use a common framework enables easier sharing of lessons learned.) From this analysis, we call for a deepening of systems change work in international PYD efforts through the following actions led by various stakeholder groups.

\section{Call to Action for All Stakeholders}

- Leave egos at the door. Collaborative systems change happens only when stakeholders are willing to share the power and the work-as well as credit for success and accountability for correcting setbacks. This involves hearing and amplifying the role of diverse actors, including young people. Our cases show how youth outcomes improved when stakeholders listened to young people, incorporated their participation, and leveraged their leadership. "Diverse voices" also include those typically excluded 


\section{Building Youth Infrastructure}

from policymaking and government systems, such as community institutions, small businesses, and parents. It is vital to involve stakeholders from all political sides so they will persevere when political leadership changes, rather than undermine the effort.

- Find (and fund) local backbone organizations. While international actors may offer value in a discrete, facilitative role, a transition strategy to a local organization must be planned from the beginning. Establishing a local legacy organization may be an effective strategy.

- Balance product with process. Ambitious performance targets may motivate actors and enable creative thinking about service delivery and system-level reforms. However, local ownership and sustainability are undermined when international partners drive numerical outcomes without developing the longer-term infrastructure to sustain them. Thus, "product" or outcome results should be valued to the degree that "process" changes are achieved, including improved stakeholder relationships, commitment, coordination, and accountability.

- Investments pay off over time, so lengthen program-planning time frames. While gains were made within a 5-year project period, our case studies indicated a more realistic time frame of 10 years or more to see sustained changes across a youth system. For this reason, donors could enable systems-level learning by funding retrospective studies, investing in locally driven data collection and evaluation, and informing themselves about previous and current systems change efforts.

\section{Call to Action for Governments}

- Set the tone and lead collaboratively. Government actors advanced PYD outcomes when they, alongside other system actors, committed to a shared vision for youth development. Fostering a culture of learning and mutual partnership among actors resulted in greater trust, more willingness to take risks, and continuous improvement.

- Re-imagine service delivery through networked partnership models. Government partners were most effective when they supported a broad range of existing public and private actors in service delivery and when they invested in policies, coordination, and data and accountability systems that reinforced effective service delivery. 


\section{Building Youth Infrastructure}

\section{Call to Action for International Donors}

- Re-envision donor roles. Donor investments yielded the best results when donors were committed to facilitating systems change, not just implementing a project or delivering a service. They made a long-term commitment and embraced a local visioning process. Their investments were complementary to other donor investments. They engaged as an active part of the youth system and used their convening power to influence the highest levels of national government across several ministries.

- Be patient and flexible. Flexible contractual arrangements and budgeting that allows partners to quickly reprogram funding as new evidence or opportunities arise were the most successful. Immediate service delivery outcomes rarely happened in the first year, as this was the period of trust building and developing a collaborative partner infrastructure. Results typically manifested in an exponential curve, not a straight line.

\section{Call to Action for Civil Society Organizations, Including Young People and the Private Sector}

- Work "against the grain" of competition. Local service providers supported youth in more meaningful ways when they innovated together and learned from one another. The more that these organizations formed their own coalitions-which should be formalized to raise visibility-and developed shared learning agendas, the more likely they were to influence government and funders to support their locally informed goals.

- Demonstrate the benefits of collaboration. The private sector became active contributors to positive youth outcomes when they saw tangible benefits of participation, including closer ties with local business and government leaders and an improved labor pool. Employers gained more favorable perceptions of even the most marginalized youth when they saw their positive contributions in the workplace. The onus is on state actors and CBOs to create appeal for private sector engagement, with a focus on practical and discrete roles.

- Represent faithfully. Young leaders involved in decision making represent not only themselves but also their peers. Representing well means listening to others, sharing authority, delegating tasks, and communicating diverse interests. Young leaders-and those who support them-must invest the necessary time and effort to hone these skills. 


\section{Building Youth Infrastructure}

\section{Call to Action for International Development Partners}

- Facilitate, rather than implement. As international partners, we were most effective when we assumed a facilitative role-one that was as much relational as technical. Our recruitment and professional development strategies should value interpersonal relationships, facilitation, and learning skills, not only technical expertise. Taking a systems approach has also required us to seek skill sets outside of a single sector. We are learning adaptive management practices that value local knowledge and learning.

- Build youth system resilience through data and learning. Investments in monitoring and evaluation should be designed to benefit the whole system, not only the project. Sustainable capacity-building efforts tapped into existing peer networks for continuous collaboration, learning, adaptation, and innovation across the entire system.

- Pivot the narrative. We as members of the Youth Systems Collaborative acknowledge that we must do better in our reporting and public communications. We must emphasize the accomplishments of system actors, whether donors ask for this or not, and discern incremental process changes within the system, even when they do not validate our original hypotheses.

\section{Ways Forward}

With this paper, the Youth Systems Collaborative has sought to contribute to international systems work by sharing examples of emerging lessons from the youth development space, mapped against a framework of domains and enablers that we believe are critical for sustained PYD. Moving forward, we hope that our member organizations and others will use and adapt the Youth Systems Framework as a structure for future learning, implementation design and practice, and, ultimately, advocacy efforts.

\section{Acknowledgements}

The authors wish to acknowledge colleagues who shared their experiences and especially the comments on earlier drafts of this paper provided by Bonnie Politz, Meaghan Koudelka, Eric Johnson, Kristin Brady, Petula Nash, Melanie Sany, Helen Boyle, Matthew Breman, Thomas Brownlee, Debby Kimble, Sylvia Ellison, Enrique Roig, and Sarka Sengezener. 
Journal of Youth Development | http://jyd.pitt.edu/ | Vol. 16 Issue 2-3 DOI 10.5195/jyd.2021.1030

Building Youth Infrastructure

\section{References}

Academy for Educational Development. (2003). 7 elements of a youth development infrastructure. Author.

Academy for Educational Development. (2004). Going to SCALE: System-wide collaborative action for livelihoods and the environment. Author. https://rmportal.net/library/content/usaid-scalecollection/scale-materials/scale-publications/going-to-scale-2013-system-wide-collaborativeaction-for-livelihoods-and-the-environment-english/view

Alvarado, G., Skinner, M., Plaut, D., Moss, C., Kapungu, C., \& Reavley, N. (2017). A systematic review of positive youth development programs in low-and middle-Income countries. USAID YouthPower Learning, Making Cents International. https://pdf.usaid.gov/pdf docs/PA00MR58.pdf

The California Endowment. (2016). A new power grid: Building healthy communities at year 5. https://california.foundationcenter.org/reports/a-new-power-grid-building-healthy-communitiesat-year-5/

Blum, R., Moore, A., Moroz, E., Felix, E., Aldredge, J. M., \& Jesse, C. (2020). A review of USAID YouthPower activities. USAID YouthPower Learning, Making Cents International. https://www.edulinks.org/sites/default/files/media/file/YouthPower\%20T0\%20Review\%20Final\%20Report.pdf

Conroy, K., \& Kessler, A. (2019). The results achieved by programmes that use the market systems development approach: A narrative synthesis of current evidence. BEAM Exchange. https://beamexchange.org/uploads/filer_public/f8/41/f841de6c-ac4d-4dae-a9c2843487fc0fb1/beam evidence review 2019 final.pdf

Cyr, H. (2017). Akazi Kanoze 2: Cost analysis report. Education Development Center, Inc. and The Mastercard Foundation. http://idd.edc.org/sites/idd.edc.org/files/Cost\%20Analysis\%20Report.pdf

Cytron, N. (2010, Spring). Improving the outcomes of place-based initiatives. Community Investments, 22(1). https://core.ac.uk/download/pdf/6231639.pdf

DevLearn. (2019). Via outcome harvesting report. https://devlearn.co.uk/wpcontent/uploads/2020/12/Harvest-Report-IYFOH-.pdf

Education Development Center, Inc. (2016). Private sector partnership and out-of-school youth development: The MYDev Experience. USAID. https://www.edc.org/sites/default/files/uploads/MYDEV Publication.pdf

Equal Measure. (2019). StriveTogether evaluation report: 2015-2017 executive summary. https://www.strivetogether.org/wp-content/uploads/2020/05/ST-Evaluation-ExecutiveSummary Final-for-Discussion 14June19.pdf 
Gibbs, E., Jones, C., Atkinson, J., Attfield, I., Bronwin, R., Hinton, R., Potter, A., \& Savage, L. (2020). Scaling and 'systems thinking' in education: Reflections from UK aid professionals. Compare: $A$ Journal of Comparative and International Education, 51(1), 137-156. https://doi.org/10.1080/03057925.2020.1784552

Hinson, L., Kapungu, C., Jessee, C., Skinner, M., Bardini, M., \& Evans-Whipp, T. (2017). YouthPower positive youth development measurement toolkit. USAID YouthPower Learning, Making Cents International. https://www.youthpower.org/positive-youth-development-toolkit

Ignatowski, C., Ski, S., Smith Hughes, C., \& Hilber, A. M. (2020). Assessment of positive youth development (PYD), including the experience and contributions of YouthPower. USAID Health Evaluation and Applied Research Development Project, University Research Company.

Ignatowski, C. (June 2018). Youth Systems Collaborative: Research framework background paper. Unpublished manuscript.

Kania, J., \& Kramer, M. (2011, Winter). Collective impact. Stanford Social Innovation Review. https://ssir.org/articles/entry/collective impact

Kania, J., Kramer, M., \& Senge, P. (2018). The water of systems change. FSG. https://www.fsg.org/publications/water of systems change

Management Systems International. (2016). Scaling up-From vision to large-scale change: $A$ management framework for practitioners. ( $3^{\text {rd }}$ ed.). https://www.msiworldwide.com/sites/default/files/additional-resources/2018-

\section{1/ScalingUp 3rdEdition.pdf}

Meadows, D. H. (2015). Thinking in systems: A primer. Chelsea Green Publishing.

Neild, R., \& Balfanz, R. (2006). Unfulfilled promise: The dimensions and characteristics of Philadelphia's dropout crisis, 2000-2005. Philadelphia Youth Network, The Johns Hopkins University, and University of Pennsylvania.

Nippard, D., Hitchins, R., \& Elliott, D. (2014). Adopt-adapt-expand-respond: A framework for managing and measuring systemic change processes. The Springfield Centre for Business in Development.

Perlman Robinson, J., Curtiss, M., \& Hannahan, P. (2020). Millions learning real-time scaling labs: Emerging findings and key insights. Center for Universal Education at Brookings. https://www.brookings.edu/research/millions-learning-real-time-scaling-labs-emerging-findingsand-key-insights/

Roth, B. J., \& Walsh, E. (2016). Youth outreach centers in El Salvador: An evaluation prepared for USAID. University of South Carolina.

Stroh, D. P. (2015). Systems thinking for social change: A practical guide to solving complex problems, avoiding unintended consequences, and achieving lasting results. Chelsea Green Publishing. 
Journal of Youth Development | http://jyd.pitt.edu/ | Vol. 16 Issue 2-3 DOI 10.5195/jyd.2021.1030

\section{Building Youth Infrastructure}

THP Capacity Advisors. (2017). North star goals dashboard: 2016-17. Health Happens Here at The California Endowment.

Turner, S., Merchant, K., Kania, J., \& Martin, E. (2012, July). Understanding the value of backbone organizations in collective impact: Part 2. Stanford Social Innovation Review.

https://ssir.org/articles/entry/understanding the value of backbone organizations in collective impact 2\#

U.S. Agency for International Development. (2012). Realizing the demographic opportunity: USAID Youth in development policy.

https://www.usaid.gov/sites/default/files/documents/1870/Youth in Development Policy 0.pdf

U.S. Agency for International Development. (2014). Local systems: A framework for supporting sustained development. https://www.usaid.gov/policy/local-systems-framework

Walsh, J. (1999). The eye of the storm: Ten years on the front lines of new futures. The Annie E. Casey Foundation. https://www.aecf.org/resources/the-eye-of-the-storm/ 